\title{
CONTROLE DE MONO E DICOTILEDÔNE AS NA CULTURA DE SOJA EM PÓS-EMERGÊNCIA, ATRAVÉS DA COMBINAÇÃO DE MEFLUIDIDE E BENTAZON
}

\section{RESUMO}

O presente trabalho buscou uma alternativa de solução para o problema através da mistura, no tanque, dos agroquímicos mefluidide e bentazon, aplicada após a emergência total da cultura e das plantas infestantes. As doses dos componentes usados no experimento em $\mathrm{kg} / \mathrm{ha}$, foram, para o mefluidide, $0,000-0,144-0,288 \mathrm{e}$ 0,480 e, para o bentazon, $0,000-0576-0,864$ e 1,152 combinadas entre si. O delineamento estatístico foi o de blocos ao acaso.

No momento da aplicacão a soja iniciava o seu terceiro trifólio e as principais plantas daninhas presentes no experimento, carurú (Amaranthus spp), carrapicho-de-carneiro (Acanthospermum hispidum DC), guanxuma (Sida spp), quenopólio (Chenopodium album L.), da classe das dicotiledôneas, e capim-marmelada (Brachiaria plantaginea (Link) Hitcl), capimpé-de-galinha (Eleusine indica (L.) Gaertm), da classe das monocotiledôneas, estavam em diferentes estádios de desenvolvimento.

Os resultados obtidos confirmaram a ação definida dos componentes na calda, mefluidide, sobre o grupo das monocotiledôneas e bentazon sobre o grupo das dicotiledôneas. Misturados, entretanto, a adição de um melhorou a atividade do outro sobre o grupo de plantas que controla.

Sintomas fitotóxicos somente foram observados nos tratamentos com mefluidide solitário.

Os tratamentos, quanto à produção, não
E.M. PAULO*; M.A. OLIVEIRA**; N.M.P. TOLEDO*** \& R. FORSTER***

* Eng." Agr.; CEC Instituto Agronômico, Campinas, São Paulo.

** 3M do Brasil Ltda., 13.100, Campinas, São Paulo.

*** Pesq. Científico, Instituto Agronômico, Caixa Postal, 28 - 13.100, Campinas, São Paulo.

diferiram estatisticamente da testemunha capinada. No controle total das plantas infestantes as misturas não diferiram estatisticamente entre si.

A extensão numérica no controle de dicotiledôneas, bem como a interação estatística entre os compostos indica a existência de ação sinérgica da mistura.

PALAVRAS-CHAVE: plantas daninhas, soja, mefluidide, bentazon, mistura de tanque.

\section{SUMMARY}

CONTROL OF GRASSES AND BROADLEAVES IN SOYBEAN CROP WITH MEFLUIDIDE AND BENTAZON TANKMIX.

The tankmix of mefluidide and bentazon offers a possibility for solution of the mixed weed population in soybean crop. The mefluidide rates applied in the experiment were $0.000-$ $0.144-0.288-0.480 \mathrm{~kg}$ i.a./ha, and for bentazon $0.000-0.576-0.864-1.152$ isolated or mixed in a randomized blocks design experiment.

At spraying time soybean were at the leaves stage and the predominant weeds were Amaranthus sp., Acanthospermum hispidum, Sida sp., Chenopodium album, Brachiaria plantaginea, Digitaria sanguinalis, Eleusine indica.

The tankmixed spray showed a wide herbicide activity, more effective than the control of 
any of the herbicides applied alone due to a sinergistic action.

KEYWORDS: weeds, Glycine max, mefluidide, bentazon, tankmix.

\section{INTRODUÇÃO}

A tecnologia da cultura da soja (Glycine $\max (\mathrm{L})$ Merrill) j á adotou, como prática consagrada, o uso de herbicidas no controle das plantas daninhas.

Estudos com agroquímicos, para essa finalidade, têm sido realizados com aplicação anterior ao plantio, seguida de sua incorporação do solo, ou a pré-emergência da soja $(5,6,12,17)$. Resultados positivos também são encontrados com compostos pulverizados após a emergência da cultura $(4,11,15,16,20,21,22)$.

Os herbicidas experimentados, entretanto, mostram uma ação mais acentuada ou sobre as monocotiledôneas ou sobre as dicotiledôneas, carecendo, ainda a soja, para o controle conjunto de ambos os grupos de infestantes, de solução satisfatória através de um único composto. Havendo presença de ambos os grupos nas áreas cultiváveis, em número limitante à produtividade, existe a necessidade de se combinar compostos, com aplicação associada ou simultânea $(3,7,8,13,23)$, para que se processe o pleno controle das invasoras.

As associações que requerem sua incorporação ao solo têm revelado maior segurança do que as aplicadas à pré-emergência posto que, por vezes, estas apresentam ação injuriosa à soja $(7,8,13)$.

Tentativas de combinações, aspergidas sobre a população de soja e plantas daninhas, demonstraram ocorrer queda, na eficiência de um dos componentes, sobre o grupo de plantas que controla (21).

As aplicações simultâneas de herbicidas $(3,8,21)$, apesar de atenderem satisfatoriamente às necessidades de controle, como também aquelas que exigem incorporação ao solo, contam com o inconveniente de onerarem os custos de produção, por exigirem uma operação agricola adicional.

O bentazon pela sua alta eficiência no controle das dicotiledõneas $(3,15,19$, 23) tem se destacado como herbicida de pós-emergência para a soja. O mefluidide, regulador de crescimento para a cultura da cana, apresenta resultados de seletividade à soja e de atividade sensibilizadora nas garmíneas quando aspergido após a emergência $(1,2)$.

A atuação, praticamente definida, de cada um destes compostos sobre as mono e dicotiledõneas, bem como a translocação similar de ambos os produtos nas plantas $(2,18)$ foram indicativas de uma associação eficiente.

$\mathrm{O}$ presente trabalho buscou, através da mistura de bentazon e mefluidide, no tanque, uma alternativa de solução para o controle das plantas daninhas na cultura da soja.

\section{MATERIAL E MÉTODOS}

O experimento foi instalado no Centro Experimental de Campinas, em um Latossolo Roxo, cujas características químicas são mostradas no quadro 1.

O delineamento estatístico adotado foi o de blocos ao acaso, com três repetições, utilizando-se quatro niveis de cada herbicida, obtendo-se um experimento fatorial $4 \times 4$.

Os tratamentos estudados foram: mefluidide $(1)=(\mathrm{N}-2,4$-dimetil-5-(trifluorometil) sulfonil) amino) fenil) aceta mida) e bentazon (2) $=(3$-isopropil-2,1,3benzotiadiazinona-( 4 )-2,2 - dióxido ), nas doses, em kg/ha : 0,144(E1) - 0,288(E2) $0,480(\mathrm{E} 3)$ e $0,576(\mathrm{~B} 1)-0,864(\mathrm{~B} 2)-1,152$ (B3), respectivamente, com aplicações isoladas e combinadas entre si, exceto a combinação E1Bo, uma testemunha capinada e outra infestada com plantas daninhas.

A semeadura da soja, cultivar IAC-2, foi realizada no dia 30/01/79, em sulcos espaçados de $1,0 \mathrm{~m}$ dispostos no sentido longitudinal das parcelas, as quais possuiam as dimen sões de $2,5 \mathrm{~m}$ de largura e $5,0 \mathrm{~m}$ de comprimento.

(1) Usado na formulação comercial de Embark.

(2) Usado na formulação comercial de Basa gran. 
A adubação, potássica e fosfatada, sob recomendação baseada na análise do solo (Quadro 1), bem como os tratamen- tos fitossanitários, estiveram dentro da normalidade para a cultura.

Juadro 1 - Resultados das análises químicas de amostra do solo do local do experimento. 1979.

\begin{tabular}{|c|c|c|c|c|c|c|}
\hline \multirow{2}{*}{$\begin{array}{l}\text { Matéria } \\
\text { orgânica }\end{array}$} & \multirow{2}{*}{$\mathrm{pH}$} & \multicolumn{3}{|c|}{ e. $\mathrm{mg} / 100 \mathrm{ml}$ de TFSA } & \multicolumn{2}{|c|}{ ug/ml de TFSA } \\
\hline & & $\mathbf{A l}+++$ & $\mathrm{Ca}++$ & $\mathbf{M g}$ & $\mathbf{K}$ & $\mathbf{P}$ \\
\hline $\begin{array}{c}96 \\
3,6\end{array}$ & 5,5 & 0,2 & 2,1 & 1,6 & 78 & 5 \\
\hline
\end{tabular}

A soja, na sua totalidade, emergiu em $07 / 02 / 79$, sendo processada a aplicação 16 dias após, no intervalo das $15: 20$ às 16 :20 horas (10), com nebulosidade estimada em $40 \%$, boa umidade no solo e sem presença de ventos intervenientes. Nessa operação, as caldas agroquímicas foram as pergidas à pressão de 3,164 $\mathrm{kg} / \mathrm{cm} 2$, mantida constante por meio de injeção de $\mathrm{CO} 2$ no tanque de um pulverizador costal com capacidade volumétrica para 5,0 1 de líquido. O pulverizador es- tava munido com uma barra metálica equipada com cinco bicos 80.02, distanciados $0,5 \mathrm{~m}$ um do outro. O gasto de água na aspersão de cada tratamento foi equivalente a 6601 / ha.

No momento da aplicação, a soja emitia o seu terceiro trifólio e apresentava porte médio de $0,18 \mathrm{~m}$. As plantas daninhas, presentes nas unidades experimentais, estavam em diferentes estádios de desenvolvimento (Quadro 2).

Quadro 2 - Estádios de desenvolvimento das plantas daninhas, presentes nas unidades experimentais, no momento da aplicação.

\begin{tabular}{llcc}
\hline Nome comum & Nome cientifico & $\begin{array}{c}\text { Altura } \\
\text { média } \\
\text { (cm) }\end{array}$ & $\begin{array}{c}\text { Número } \\
\text { de } \\
\text { folhas }\end{array}$ \\
\hline Carurú & Amaranthus spp & 15 & 6 \\
Carrapicho-de-carneiro & Acanthospermun hispidum & 10 & 8 \\
Guanxuma & Sida spp & 5 & 4 \\
Quenopódio & Chenopodium atbum & 12 & 8 \\
Capim-marmelada & Brachiaria plantaginea & 15 & 4 \\
Capim-pé-de-galinha & Eleusine indica & 5 & 2 \\
\hline
\end{tabular}

A primeira precipitação pluviométrica somente ocorreu 144 horas depois de aplicados os tratamentos (9).

A avaliação da eficiência herbicida dos compostos, e suas diferentes misturas, foi realizada no dia 23/03 utilizando-se o método da contagem e classificação das plantas daninhas remanescentes (Quadro 3), tomando-se, ao acaso, três amostras de $0,2 \mathrm{~m}^{2}$ no interior das parcelas (14) .
Todas as parcelas receberam capina em 26/03.

Acolheita e a contagem da população de soja foram processadas no dia 06/06/79.

Foram analisadas estatisticamente a produção, a população final de soja e de monocotiledôneas e dicotiledôneas separadamente e somadas. 


\section{RESULTADOS E DISCUSSÃO}

\section{Controle de dicotiledôneas}

O número de plantas daninhas dicotiledôneas remanescentes às aplicações das caldas herbicidas é mostrado no quadro 3 onde se observa a ação distinta do mefluidide e do bentazon, quando aplicados isoladamente sobre este grupo de plantas daninhas. Esse fato é comprovado através da diferenciação estatística verificada entre os tratamentos. Nesta condição, o mefluidide mostrou não reduzir numericamente estas invasoras, se bem que o caruru tenha acusado suscetibilidade a este herbicida, apresentando, como sintomatologia fitotóxica, redução no porte e soldamento da folha. O bentazon, por sua vez, demonstrou atividade, embora o aumento da dose não tenha proporcionado melhora na eficiência de controle. Os resultados de controle encontrados para este herbicida concordam com os de outros autores $(3,15,23)$.

$\mathrm{Na}$ associação dos compostos, as dicotiledôneas, para uma mesma dose de mefluidide, diminuiram seguindo $\mathrm{o}$ aumento das quantidades de bentazon incluidas à calda ; mostrando-se o controle tão mais eficiente quanto maior a dose dos componentes misturados.

Observando-se a figura 1 percebe-se que o mefluidide, quando em mistura, promove a diminuição das plantas daninhas dicotiledôneas linearmente e o bentazon conforme uma curva, de acordo com o aumento das doses, ocorrendo interação significativa entre os dois herbicidas.

\section{Controle de monocotiledôneas}

Observando-se a figura 2, que representa o número de monocotiledôneas remanescentes aos tratamentos, nota-se a não atividade do bentazon sobre este grupo de plantas e que mesmo quantidades crescentes desse composto, aplicadas na ausência do mefluidide, favorecem o surgimento destas espécies daninhas nas unidades experimentais. O maior aparecimento de gramíneas, neste caso, possivelmente é devido ao controle de dicotiledôneas exercido pelo bentazon, elimi- nando assim, a competição destas espécies com as monocotiledôneas por água, luz, nutrientes, e espaço.

As monocotiledôneas apresentaram diminuição nos tratamentos de mefluidide, em aplicação isolada sendo menor o número destas plantas daninhas na maior dose aplicada.

Nos tratamentos com misturas dos compostos, o número de gramíneas tendeu a diminuir quando, para uma mesma dose de mefluidide, incluiram-se doses crescentes de bentazon. Exceção ocorreu na dose B1 de bentazon associada às de mefluidide, para as quais houve um aumento no número de gramíneas com $\mathrm{o}$ aumento da dose deste último.

O melhor controle verificado aconteceu na combinação de $0,480 \mathrm{~kg} /$ ha de mefluidide com $1,152 \mathrm{~kg} /$ ha de bentazon.

$\mathrm{O}$ alto coeficiente de variação obtido pela análise estatística e o baixo número de plantas daninhas monocotiledôneas presentes nas parcelas testemunhas, podem ter concorrido para o não aparecimento de diferenças estatisticamente significativas entre os tratamentos ao nível de $5 \%$ de probabilidade (Quadro 3).

\section{Controle total}

O quadro 3 mostra a soma de monocotiledôneas e dicotiledôneas remanescentes às aplicações dos herbicidas, onde se verifica que todas as misturas testadas diferiram significativamente da testemunha sem capina.

$\mathrm{Na}$ figura 3 percebe-se que o número de plantas daninhas decresceu com o aumento das quantidades pulverizadas de ambos os agroquímicos sendo esta queda linear para o mefluidide e quadrática para o bentazon.

Este resultado é similar ao encontrado para as dicotiledôneas visto que este grupo de plantas foi o que prevaleceu no experimento, sem ser entretanto, estatisticamente significativa a interação entre os dois compostos ao nível de $5 \%$ de probabilidade.

4. Andamento da cultura e resultados de produção

A soja, no estádio em que recebeu a 
aplicação das diferentes doses de bentazon e suas misturas com mefluidide não apresentou sintomas de fito toxicidade.

Injúrias à cultura foram verificadas para o mefluidide aplicado isoladamente, sendo sua agressividade proporcional à dose pulverizada, sem entretanto, reduzir a população de plantas (Quadro 4). Tal fato explica a menor produção que foi observada na combinação E3Bo (Quadro 4 ).

Verifica-se ainda que as melhores produções foram alcançadas com a menor dose desse agroquímico pulverizada em associação com o bentazon.

Apesar da análise estatística não acusar diferenças entre a testemunha sem capina e a testemunha capinada, es- ta apresentou uma produção superior, de pratilamente duas vezes, o mesmo se dando para os tratamentos de bentazon em aplicação isolada (Quadro 4 ).

Observando-se a figura 4, nota-se que a produção decresceu linearmente à medida que quantidades maiores dos agroquímicos foram combinadas, exceção para a dose E2 onde houve um leve aumento para doses crescentes de bentazon.

Analisando-se os componentes lineares da análise estatística, $\mathrm{E}^{\prime}$ e $\mathrm{B}^{\prime}$ da figu ra 4, percebe-se que, em mistura, o decréscimo na produção é provocado mais pelo mefluidide do que pelo bentazon, visto que ele possui o componente linear, que é negativo, maior. 
Quadro 3 - Total de plantas daninhas remanescentes às aplicaçöes das caldas herbicidas no momento da avaliaçăo.

\begin{tabular}{|c|c|c|c|c|c|c|c|c|c|c|c|c|c|c|c|c|}
\hline \multicolumn{17}{|c|}{ TRATAMENTOS } \\
\hline PLANTAS DANINHAS & E1 & E1 & E1 & E2 & E2 & E2 & E3 & E3 & E3 & E2 & E3 & E0 & E0 & E0 & E0 & RESUMO ESTA- \\
\hline DICOTILEDONEAS & B1 & $\mathbf{B 2}$ & B3 & B1 & B2 & B3 & B1 & B2 & B3 & B0 & B0 & B1 & B2 & B3 & B0 & TISTICO (1) \\
\hline $\begin{array}{l}\text { Carrapicho-de-carneiro } \\
\text { Caruru } \\
\text { Guanxuma } \\
\text { Quenopódio } \\
\text { Outras dicotiledôneas }\end{array}$ & $\begin{array}{r}0 \\
15 \\
1 \\
14 \\
1\end{array}$ & $\begin{array}{r}0 \\
6 \\
1 \\
11 \\
6\end{array}$ & $\begin{array}{l}0 \\
4 \\
1 \\
5 \\
5\end{array}$ & $\begin{array}{r}0 \\
6 \\
0 \\
3 \\
10\end{array}$ & $\begin{array}{l}0 \\
8 \\
0 \\
2 \\
7\end{array}$ & $\begin{array}{l}0 \\
1 \\
0 \\
0 \\
7\end{array}$ & $\begin{array}{l}0 \\
0 \\
1 \\
6 \\
3\end{array}$ & $\begin{array}{l}0 \\
1 \\
0 \\
1 \\
3\end{array}$ & $\begin{array}{l}0 \\
2 \\
0 \\
1 \\
0\end{array}$ & $\begin{array}{r}82 \\
543 \\
28 \\
7 \\
19\end{array}$ & $\begin{array}{r}78 \\
573 \\
21 \\
12 \\
22\end{array}$ & $\begin{array}{l}0 \\
4 \\
0 \\
3 \\
8\end{array}$ & $\begin{array}{r}0 \\
23 \\
0 \\
4 \\
6\end{array}$ & $\begin{array}{r}0 \\
28 \\
0 \\
0 \\
4\end{array}$ & $\begin{array}{r}50 \\
547 \\
28 \\
19 \\
29\end{array}$ & $\begin{array}{l}F=35,83^{* *} \\
C V=18,8 \% \\
F=0,895 n . s \\
C V=35,5 \%\end{array}$ \\
\hline TOTAL (2) & $31 \mathrm{bc}$ & $24 \mathrm{bc}$ & $15 a b c$ & $19 \mathrm{abc}$ & $17 \mathrm{bc}$ & $8 a b c$ & $10 \mathrm{abc}$ & $5 \mathrm{ab}$ & $3 a$ & $679 \mathrm{~d}$ & $706 \mathrm{~d}$ & $15 \mathrm{bc}$ & $33 \mathrm{c}$ & $32 \mathrm{c}$ & $673 \mathrm{~d}$ & $\begin{array}{l}F=9,67^{* *} \\
C V=19,63 \%\end{array}$ \\
\hline \multicolumn{17}{|l|}{$\overline{\text { MONOCOTILEDONTAS }}$} \\
\hline $\begin{array}{l}\text { Capim-marmelada } \\
\text { Capim-pé-de-galinha } \\
\text { Outras monocotiledó- } \\
\text { neas }\end{array}$ & $\begin{array}{r}15 \\
26 \\
1\end{array}$ & $\begin{array}{r}3 \\
33 \\
0\end{array}$ & $\begin{array}{r}0 \\
27 \\
0\end{array}$ & $\begin{array}{r}2 \\
49 \\
0\end{array}$ & $\begin{array}{r}0 \\
32 \\
0\end{array}$ & $\begin{array}{r}0 \\
46 \\
0\end{array}$ & $\begin{array}{r}0 \\
70 \\
0\end{array}$ & $\begin{array}{r}2 \\
16 \\
0\end{array}$ & $\begin{array}{r}2 \\
20 \\
0\end{array}$ & $\begin{array}{r}1 \\
35 \\
1\end{array}$ & $\begin{array}{r}0 \\
36 \\
0\end{array}$ & $\begin{array}{r}4 \\
11 \\
0\end{array}$ & $\begin{array}{r}45 \\
23 \\
1\end{array}$ & $\begin{array}{l}18 \\
63 \\
0\end{array}$ & $\begin{array}{l}17 \\
15 \\
0\end{array}$ & \\
\hline TOTAL (2) & 42 & 36 & 27 & 51 & 32 & 46 & 70 & 16 & 22 & 37 & 36 & 15 & 69 & 81 & 32 & \\
\hline TOTAL GERAL (2) & $73 a$ & $60 \mathrm{a}$ & $42 a$ & $70 \mathrm{a}$ & $49 a$ & $54 a$ & $80 \mathrm{a}$ & $21 \mathrm{a}$ & $25 a$ & $716 \mathrm{~b}$ & $742 \mathrm{~b}$ & $30 a$ & $102 \mathrm{ab}$ & $113 \mathrm{ab}$ & $705 b$ & \\
\hline
\end{tabular}

(1) Os cálculos estatísticos foram efetuados com os dados transformados em $y=\log (x+1)$.

(2) Letras comuns na mesma linha indicam que os traços não diferem entre si a $5 \%$ pelo teste Tukey. 

Quadro $4-$ Resultados estatísticos da produção, média de três repetições, e da população de soja
por tratamento.

\begin{tabular}{|c|c|c|}
\hline $\begin{array}{l}\text { Combinações das doses de } \\
\text { mefluidide e bentazon }\end{array}$ & $\begin{array}{l}\text { Produçăo } \\
\text { média }(\mathrm{kg})\end{array}$ & $\begin{array}{l}\text { Populaçăo } \\
\text { de soja }\end{array}$ \\
\hline E1B1 & $0,607 \mathrm{a}$ & 97 \\
\hline E1B2 & $0,540 \mathrm{ab}$ & 73 \\
\hline E1B3 & $0,637 \mathrm{a}$ & 105 \\
\hline E2B1 & 0,590 a & 77 \\
\hline E2B2 & $0,510 \mathrm{ab}$ & 97 \\
\hline E2B3 & $0,530 \mathrm{ab}$ & 80 \\
\hline E3B1 & $0,480 \mathrm{ab}$ & 55 \\
\hline E3B2 & $0,383 a b$ & 87 \\
\hline E3B3 & $0,426 \mathrm{ab}$ & 83 \\
\hline E2BO & $0,396 \mathrm{ab}$ & 74 \\
\hline E3B0 & $0,160 \mathrm{~b}$ & 78 \\
\hline E0B1 & $0,433 \mathrm{ab}$ & 93 \\
\hline E0B2 & $0,556 \mathrm{ab}$ & 76 \\
\hline E0B3 & $0,553 \mathrm{ab}$ & 76 \\
\hline Testemunha sem capina & $0,260 \mathrm{ab}$ & 55 \\
\hline Testemunha capinada & $0,540 \mathrm{ab}$ & 42 \\
\hline Resumo Estatístico (1) & $\begin{array}{l}\mathrm{F}=2,80^{* *} \\
\mathrm{CV}=27,92 \%\end{array}$ & $\begin{array}{l}F=1,18 \text { n.s. } \\
\mathrm{CV}=17,90 \%\end{array}$ \\
\hline
\end{tabular}

(1) Cálculos estatísticos efetuados com os dados transformados em $\mathrm{Y}=\sqrt{\mathbf{x}}$

$\mathrm{E}=$ doses de mefluidide

$\mathrm{B}=$ doses de bentazon

$\begin{array}{lll}\mathrm{E} 1=0,144 \mathrm{~kg} / \mathrm{ha} & \mathrm{E} 2=0,288 \mathrm{~kg} / \mathrm{ha} & \mathrm{E} 3=0,480 \mathrm{~kg} / \mathrm{ha} \\ \mathrm{B} 1=0,576 \mathrm{~kg} / \mathrm{ha} & \mathrm{B} 2=0,864 \mathrm{~kg} / \mathrm{ha} & \mathrm{B} 3=1,152 \mathrm{~kg} / \mathrm{ha}\end{array}$

(2) Letras comuns indicam resultados sem diferenças estatísticas entre si ao nivel de $5 \%$ de probabilidade por Tukey. 
Figura 1 - Número de plantas daninhas dicotiledôneas, transformado em

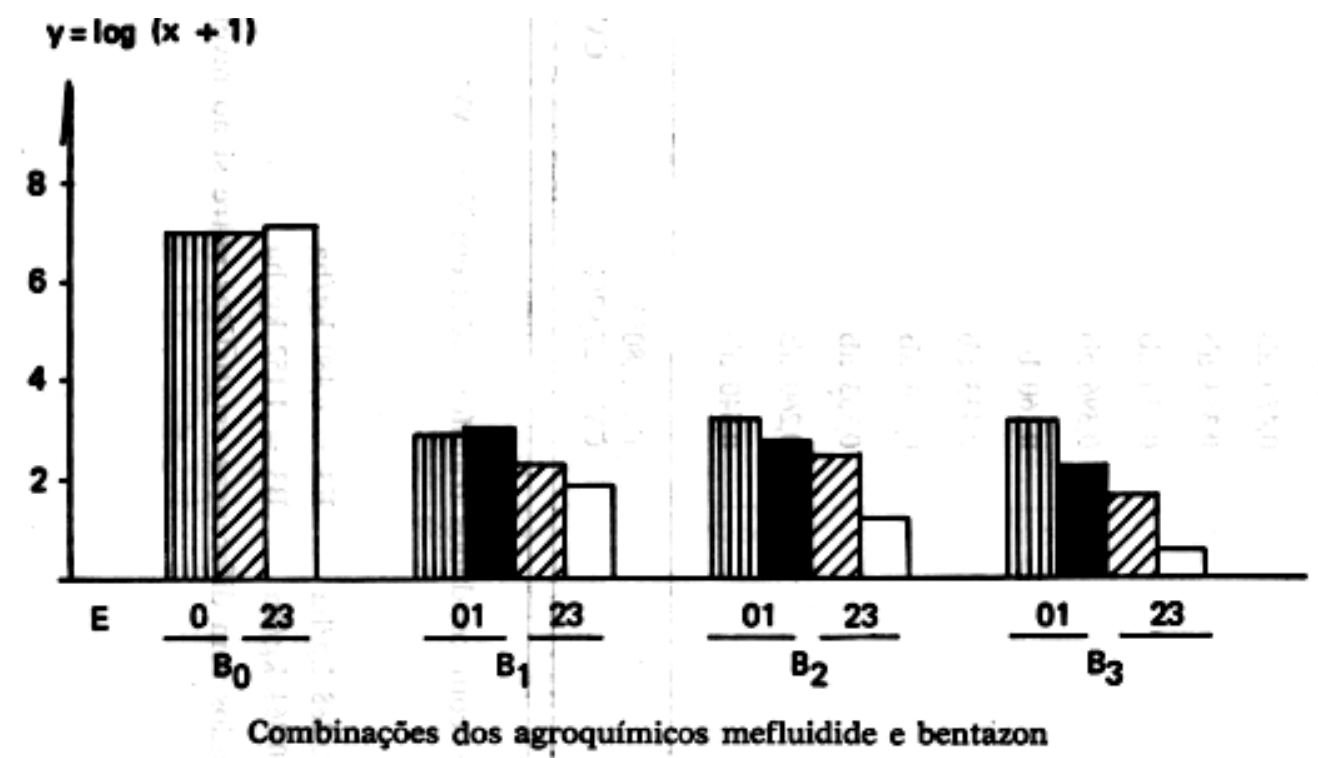

Doses em kg i.a./ha

\begin{tabular}{ll}
\hline $\mathbf{E}=$ mefluidide & $\mathrm{B}=$ bentazon \\
\hline $\mathbf{0}=0,000$ & $0=0,000$ \\
$1=0,144$ & $1=0,576$ \\
$2=0,288$ & $2=0,864$ \\
$3=0,480$ & $3=1,152$ \\
\hline
\end{tabular}

Análise Estatística

\begin{tabular}{ccc}
\hline \multicolumn{2}{c}{ Dicotiledôneas } \\
\hline Trat. & $40,26^{* *}$ \\
E & & $9,36^{* *}$ \\
& E ' & $18,35^{* *}(-)$ \\
& E'" & 0,36 ns \\
B & & $128,88^{* *}$ \\
& B ' & $282,88^{* *}(-)$ \\
& B ' & $85,47^{* *}(-)$ \\
E x B & $3,68^{*}$ \\
CV & $19,03 \%$ \\
s & 0,214024 \\
\hline
\end{tabular}

Valores de F, coeficiente de variaçăo e desvio padräo. 
Figura 2 - Número de plantas daninhas monocotiledôneas, transformado em $y=\log (x+1)$, remanescentes aos tratamentos.

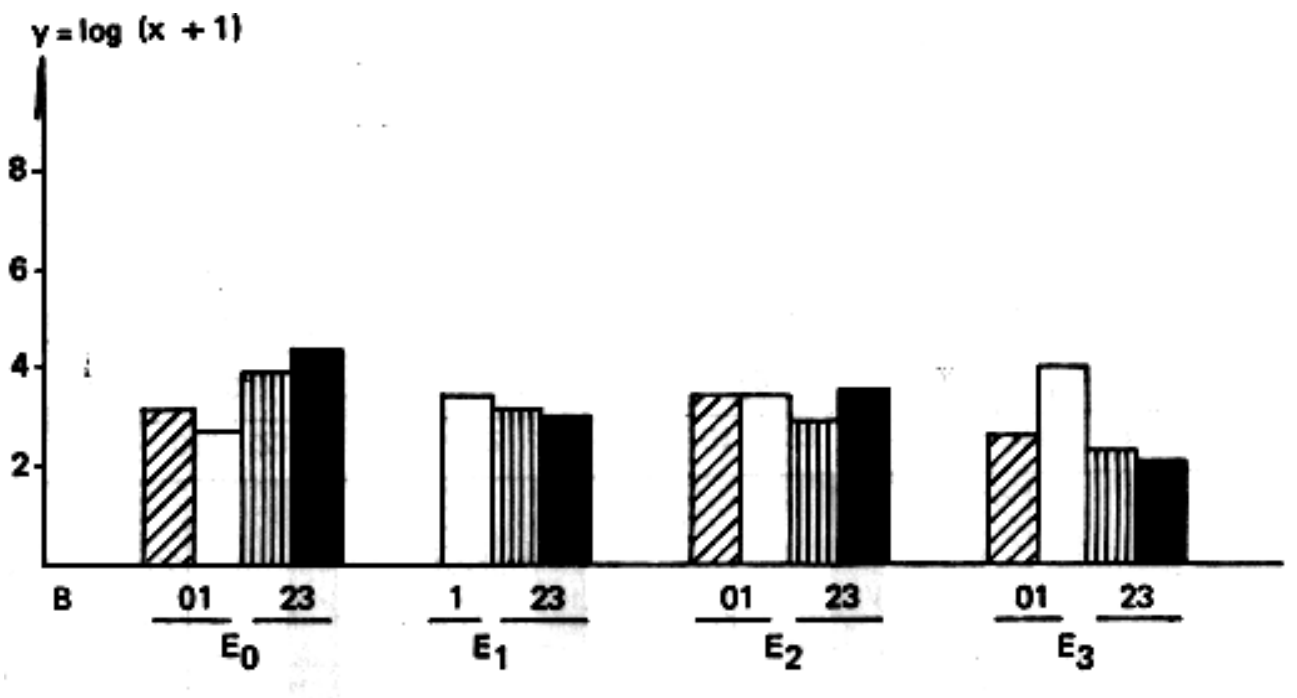

Combinações dos agroquímicos mefluidide e bentazon

Análise Estatística

\begin{tabular}{|c|c|}
\hline \multicolumn{2}{|c|}{ Monocotiledôneas } \\
\hline Trat: & 1,16 ns \\
\hline $\mathbf{E}$ & $2,62 \mathrm{~ns}$ \\
\hline $\mathbf{E}^{\prime}$ & $28,06 \mathrm{~ns}$ \\
\hline$E^{\prime \prime}$ & $0,003 \mathrm{~ns}$ \\
\hline B & $0,06 \mathrm{~ns}$ \\
\hline $\mathbf{B}^{*}$ & $0,006 \mathrm{~ns}$ \\
\hline B $^{\prime \prime}$ & $0,019 \mathrm{~ns}$ \\
\hline $\mathbf{E} \times \mathbf{B}$ & $0,10 \mathrm{~ns}$ \\
\hline $\mathrm{CV}$ & $33,08 \%$ \\
\hline $\mathbf{s}$ & 0,355383 \\
\hline
\end{tabular}

Valores de F, coeficiente de variaçăo e desvio padräo.

\begin{tabular}{ll}
\multicolumn{2}{c}{ Doses em $\mathbf{k g}$ i.a. $/$ ha } \\
\hline $\mathbf{E}=$ mefluidide & $\mathbf{B}=$ bentazon \\
\hline $0=0,000$ & $0=0,000$ \\
$1=0,144$ & $1=0,576$ \\
$2=0,288$ & $2=0,864$ \\
$3=0,480$ & $3=1,152$ \\
\hline
\end{tabular}


Figura 3 - Número total de plantas daninhas, transformado em $y=\log (x+1)$, remanescentes aos tratamentos.

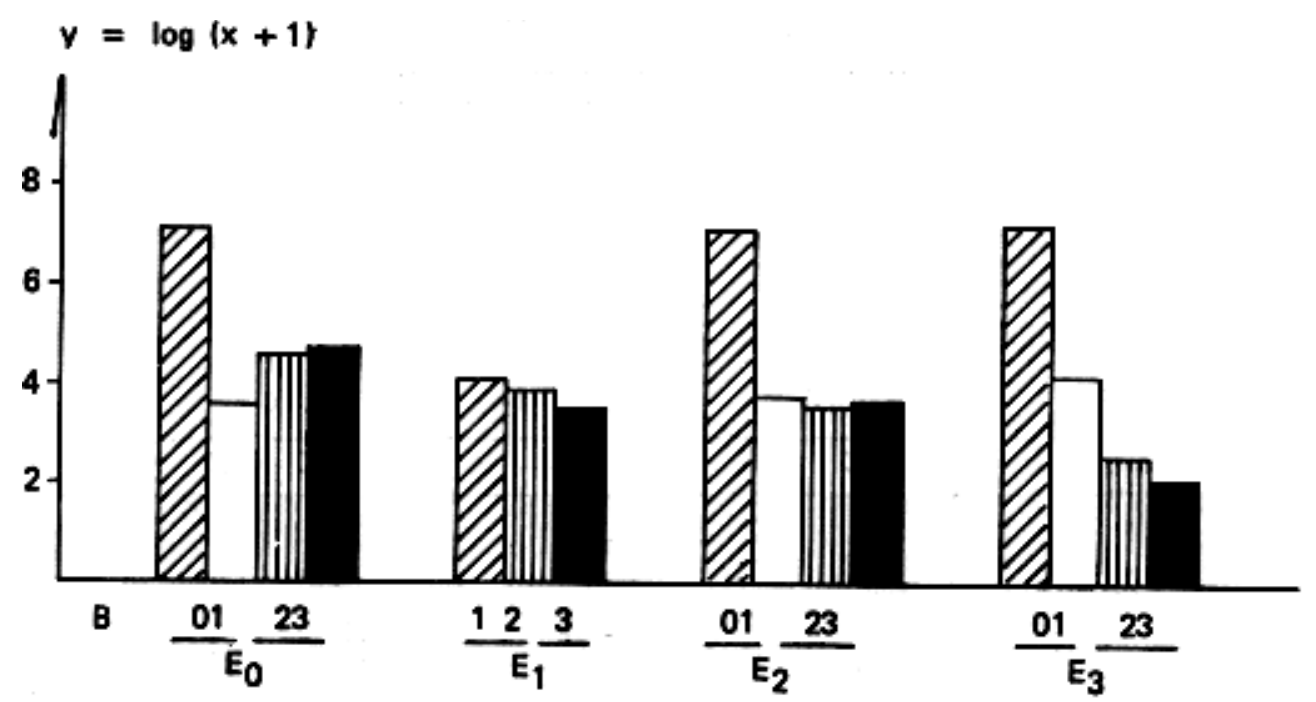

Combinações dos agroquímicos mefluidide e bentazon

Doses em kg i.a./ha

\begin{tabular}{ll}
\hline $\mathbf{E}=$ mefluidide & $\mathbf{B}=$ bentazon \\
\hline $0=0,000$ & $0=0,000$ \\
$1=0,144$ & $1=0,576$ \\
$2=0,288$ & $2=0,864$ \\
$3=0,480$ & $3=1,152$ \\
\hline
\end{tabular}

Análise Estatística

Mono+ dicotiledôneas

Trat. $\quad 8,00^{* *}$

E

$\mathrm{E}^{\prime} \quad 6,24^{* * *}(-)$

E'" $0,005 \mathrm{~ns}$

B 31,22 **

B $^{\prime} \quad 60,55^{\text {** }}$

B ', $27,20^{* *}$

E X B $2,02 \mathrm{~ns}$

CV $20,44 \%$

S $\quad 0,309484$

Valores de F, coeficiente de variação e desvio padrão. 
Figura 4 - Peso dos gräos de soja, em gramas por planta, por tratamento.

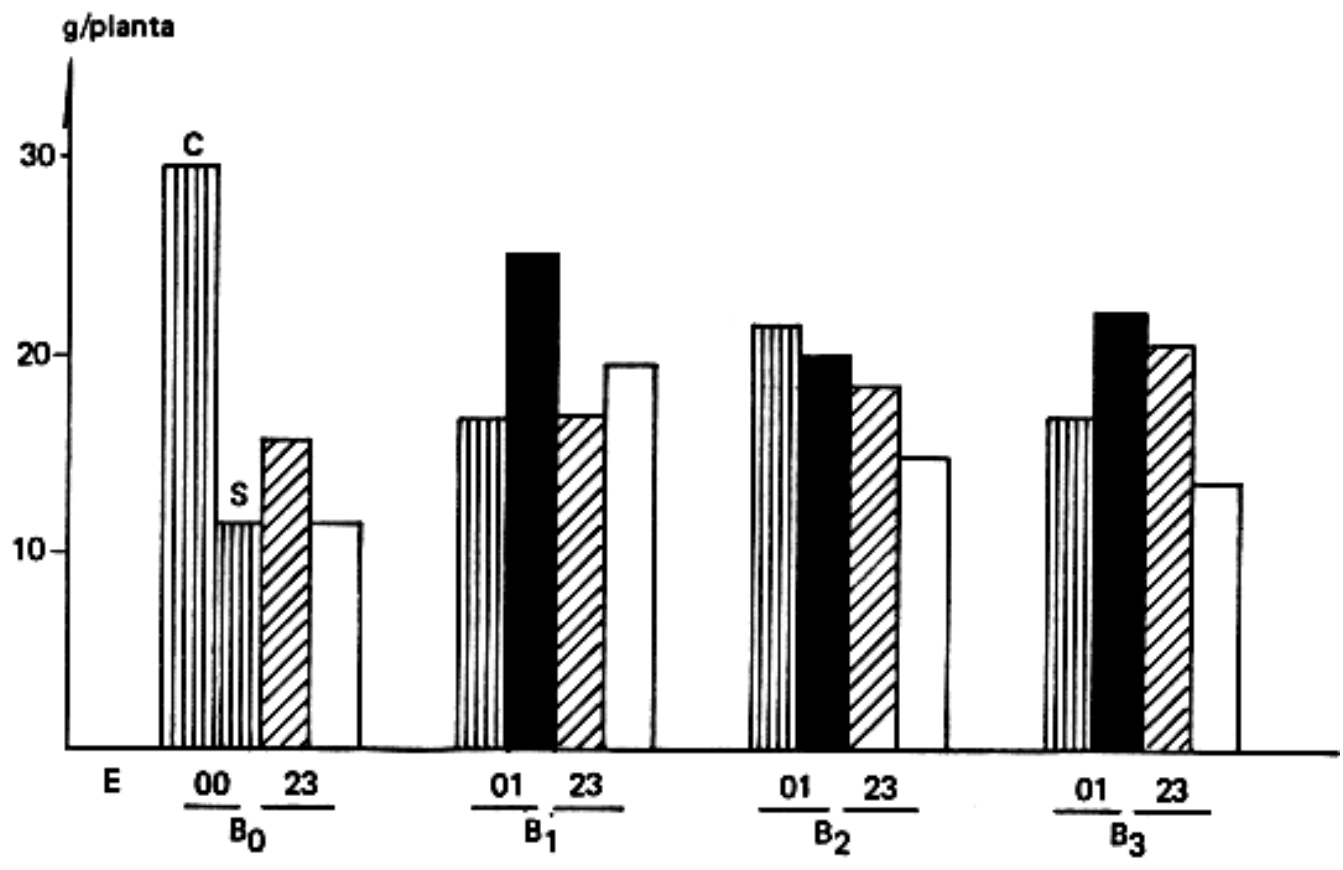

Combinaçōes dos agroquímicos mefluidide e bentazon

\begin{tabular}{|c|c|}
\hline \multicolumn{2}{|c|}{ Produção-g/planta } \\
\hline Trat: & $2,95^{\star}$ \\
\hline $\mathbf{E}$ & $6,88^{* *}$ \\
\hline $\mathbf{E}^{\prime}$ & $13,66^{* *}(-)$ \\
\hline $\mathbf{E}^{\prime \prime}$ & $0,11 \mathrm{~ns}$ \\
\hline B & $1,92 \mathrm{~ns}$ \\
\hline $\mathbf{B}^{\prime}$ & $3,64^{*}(-)$ \\
\hline B'" & $0,20 \mathrm{~ns}$ \\
\hline$E \times B$ & $7,50 \mathrm{~ns}$ \\
\hline $\mathrm{CV}$ & $16,60 \%$ \\
\hline $\mathbf{s}$ & 3,1225 \\
\hline
\end{tabular}

Valores de F, coeficiente de variaçăo e desvio padrão.

Doses em kg i.a./ha

\begin{tabular}{ll}
\hline $\mathrm{E}=$ mefluidide & $\mathrm{B}=$ bentazon \\
\hline $\mathbf{0}=0,000$ & $\mathbf{0}=0,000$ \\
$1=0,144$ & $\mathbf{1}=0,576$ \\
$2=0,288$ & $2=0,864$ \\
$3=0,480$ & $3=1,152$ \\
\hline
\end{tabular}




\section{LITERATURA GITADA}

1. Anônimo. Embark - Plant growth regulator/herbicide. International data bulletin - 3M Company.

2. Bloomberg, J.R. \& Max, L.M. Absorption and translocation of mefluidide by soybean, commom cocklebur, giant foxtail. Weed Science, Vol. 26(5): 434-440. 1978.

3. Borgo, A. \& Rosito, C. Avaliação do efeito da aplicação de misturas e combinações de herbicidas na cultura da soja. In: Seminário Brasileiro de Herbicidas e Ervas Daninhas. 12:, Fortaleza, 1978. Resumos, p. 96.

4. Borgo, A. \& Rosito. C. Resultados de aplicaçāo de herbicidas para o controle de Euphorbia heterophyla na cultura de soja. In: Seminário Brasileiro de Herbicidas e Ervas Daninhas, 12:, Fortaleza, 1978. Resumos, p. 95.

5. Carvalho, L.R.; Ruckein Filho, O. \& Davis, G.G. Herbicidas isoladas no controle as ervas daninhas da soja. In: Seminário Brasileiro de Herbicidas e Ervas Daninhas. $11:$, Londrina, 1976. Resumos, p. 71.

6. Covolo, L. \& Watt, M.R. Primeiro ensaio de competição de herbicida na cultura da soja, na regiảo de Santa Maria (RS). In: Seminário Brasileiro de Herbicidas e Ervas Daninhas. 10., Santa Maria, 1974. Resumos, p. 60.

7. Covolo, L. \& Pulver, E. Aumento de tolerância do metribuzin em soja, pela aplicaçāo com trifluralin. In: Seminário Brasileiro de Herbicidas e Ervas Daninhas, 11. , Londrina, 1976. Resumos, p. 83.

8. Cruz, L.S.P. \& Leiderman, L. Controle de plantas daninhas em cultura de soja (Glycine $\max$ (L.) Merrill) com mistura de herbicidas. Planta Daninha, 1(1): 13-17. 1978.

9. Doran, D.L. \& Andersen, R.N. Effects of simulated rainfall on bentazon activity. Weed Science, 23(2): 105-109. 1975.

10. Doran, D.L. \& Andersen, R.N. Effectiveness of bentazon applied at various times of the day. Weed Science, 24(6): 567-570, 1976.

11. Fleck, N.G. Avaliação de dosagens e épocas de aplicação do herbicida diclofop na cultura da soja para o controle de papuã (Brachiaria plantaginea). In: Seminário Brasileiro de Herbicidas e Ervas Daninhas, 12. ${ }^{\circ}$, Fortaleza, 1978. Resumos, p. 98.

12. Grassi, N. \& Leiderman, L. Dois novos herbicidas de pré-plantio incorporado para a cultura de soja. In: Seminário Brasileiro de Herbicidas e Ervas Daninhas. 10.' Santa Maria, 1974. Resumos, p. 28.
13. Honda, T.; Menegel, D. \& Machado, P.R. Controle de ervas daninhas de folhas lar. gas na cultura da soja. In: Seminário Brasileiro de Herbicidas e Ervas Daninhas, 11. ${ }^{\circ}$, Londrina, 1976. Resumos, p. 80.

14. Igue, T.; Forster, R. \& Deuber, R. Amostragem mínima em contagem de ervas em experimentos com herbicidas. In: Seminário Brasileiro de Herbicidas e Ervas Daninhas, 10., Santa María, 1974, Resumos, p. 54 .

15. Leiderman, L.; Grassi, N. \& Santos, C.A.L. Bentazon - Novo herbicida para amendoim e soja. In: Seminário Brasileiro de Herbicidas e Ervas Daninhas, 10.', Santa Maria, 1974, Resumos, p. 47.

16. Leiderman, L. \& Grassi, N. HOE 23408, novo herbicida seletivo de pós-emergência para soja. In: Seminário Brasileiro de Herbicidas e Ervas Daninhas, 11.', Londrina, 1976. Restumos, p. 70.

17. Lorenzi, H.J. \& Davis, G.C. Competiçăo de herbicidas na cultura da soja. In: Seminário Brasileiro de Herbicidas e Ervas Daninhas, 11:, Londrina, 1976. Resumos, p. 67.

18. Mahoney, M.D. \& Penner, D. Bentazon translocation and metabolism in soybean and navy bean. Weed Science, 23(4): 265-271. 1975.

19. McWorther, C.G. \& Anderson, J.M. Bentazon applied post emergence for economical control of commom cocklebur in soybeans. Weed Science, 24(4): 391-396. 1976.

20. Ramos, M. Efeito de doses e épocas de aplicação do produto HOE 23408 no controle de papua (Brachiaria plantaginea) em tratamento de pós-emergência, na cultura da soja. In: Seminário Brasileiro de Herbicidas e Ervas Daninhas, 11:, Londrina, 1976. Resumos, p. 72.

21. Ramos, M. Efeito de derivados de ácido propiônico no controle de papuã (Brachiaria plantaginea), em tratamento de pós-emergência na cultura da soja, mistura e associação com bentazon. In: Seminário Brasileiro de Herbicidas e Ervas Daninhas, 11: , Londrina, 1976. Resumos, p. 79.

22. Rozansky, A. \& Leiderman, L. Herbicida em soja: II - Produtos de pós-emergência para controle de plantas daninhas dicotiledôneas: In: Seminário Brasileiro de Herbicidas e Ervas Daninhas, 12: ${ }^{\circ}$ Fortaleza, 1978. Restumos, p. 99.

23. Rückheim Filho, O.; Venturella, L.C. \& Davis, G.C. Misturas e combinaçōes de herbicidas no controle às invasoras da soja. In: Seminário Brasileiro de Herbicidas e Ervas Daninhas, 11.', Londrina, 1976. Resumos, p. 86. 